\title{
Alterações nos fatores de competição da indústria calçadista exportadora devido à entrada de competidores asiáticos
}

\author{
Giancarlo Medeiros Pereira, ${ }^{\mathrm{a}, *}$, Miguel Afonso Sellitto ${ }^{\mathrm{b}}$, Miriam Borchardt ${ }^{\mathrm{c}}$ \\ a,*gian@unisinos.br, UNISINOS, Brasil \\ bsellitto@unisinos.br, UNISINOS, Brasil \\ 'miriamb@unisinos.br, UNISINOS, Brasil
}

\begin{abstract}
Resumo
Este artigo apresenta uma análise das modificações observadas entre 1990 e 2008 nos fatores de competição vigentes na indústria calçadista do Vale do Rio dos Sinos voltada à exportação para grandes redes de varejo nos Estados Unidos. Essas alterações resultam das novas condições de competitividade que lhes foram impostas pela entrada de competidores asiáticos, principalmente chineses, no mercado. Foi utilizada a metodologia do estudo de caso exploratório qualitativo. As principais técnicas de pesquisa foram a entrevista semiestruturada e o grupo focado com gestores especialistas. Foram entrevistados gestores praticantes e especialistas acadêmicos com atividades nas empresas. Como resultado, observou-se que os atores do processo de produção para exportação de calçados aumentaram a importância das dimensões diversidade de modelos, qualidade, inovação, velocidade e flexibilidade de produto e reduziram a importância das dimensões volume de produção e preço de venda. As dimensões design, performance e pontualidade permaneceram inalteradas. A principal contribuição do artigo é desvelar elementos que permitam a formulação de hipóteses para estudos futuros, mais completos, acerca do impacto das alterações mercadológicas sobre fatores competitivos e estratégia de produção.
\end{abstract}

Palavras-chave

Indústria calçadista. Estratégia de produção. Flexibilidade. Cadeia de suprimentos. Competitividade.

\section{Introdução}

A trajetória ascendente que a produção calçadista brasileira teve desde a década de 1960 foi baseada em produção em massa de modelos de baixo valor agregado. Como os volumes desse tipo de produto são muito elevados, a indústria calçadista nacional voltada à exportação adotou uma lógica fordista em suas instalações produtivas. 0 crescimento do setor induziu a ampliação da rede de fornecedores de insumos, equipamentos e prestadores de serviço especializados na área calçadista, formando um aglomerado empresarial especializado na região (SCHMITZ, 1998).

Usualmente denominados de clusters (SCHMITZ, 1998) ou de Sistemas Locais de Produção - SLPs (GARCIA et al., 2004), esses aglomerados empresariais em nível geográfico e setorial geraram uma estrutura que favoreceu as inter-relações no âmbito local, conferindo vantagens significativas às empresas inseridas em tais arranjos, comparadas com empresas dispersas geograficamente. Clusters como os estudados tiram proveito da aglomeração industrial reduzindo custos de transporte, custos de transação por informação imperfeita, pela rápida difusão de inovações e boas práticas de fabricação e pelo aumento da divisão do trabalho e da especialização entre as empresas. Vantagens originadas da aglomeração reforçam o arranjo e atraem novos empreendimentos, que reforçam ainda mais o arranjo produtivo local e ampliam a vantagem da aglomeração (LOMBARDI, 2003; SUZIGAN et al., 2001a,b; SCHMITZ; NADVI, 1999; KRUGMAN, 1998; SCOTT, 1998; PORTER, 1998; SCHMITZ, 1997; SONOBE; AKOTEN; OTSUKA, 2006).

Contudo, o crescimento da indústria calçadista brasileira foi repentinamente interrompido pela entrada de competidores asiáticos, notadamente 
chineses, no rol de fornecedores mundiais de calçados de baixo valor agregado. Isso ocorreu em meados da década de 1980 e se verificou apenas na área produtiva, já que atividades com maior agregação de valor, como por exemplo design, marketing e distribuição, foram mantidas na Europa e nos Estados Unidos. (SEBRAE, 1992; GEREFFI, 1999; STURGEON, 2002; FURTAD0, 2003).

A interrupção em foco alterou o perfil produtivo da indústria nacional de calçados voltada à exportação, fazendo com que buscasse migrar para mercados de maior valor agregado, os quais, até então, eram abastecidos por fabricantes de calçados localizados na Europa e nos Estados Unidos. Algumas ações observadas na indústria brasileira no período foram: desverticalização e externalização do processo produtivo por terceirização ou subcontratação, contratação de mão de obra a tempo parcial, trabalho fora do sistema de seguridade social e flexibilização da jornada de trabalho. Introduziram-se novas tecnologias e novos métodos organizacionais, procurando fugir do controle sindical e buscando romper com contratos coletivos de trabalho. Outra medida foi fechar e relocalizar as plantas produtivas de modo que se criassem novas relações de trabalho, distintas das anteriormente vigentes (PICCININI, 1995).

As mudanças descritas objetivavam incrementar a competitividade dos produtores de moda, os quais raramente têm uma relação harmoniosa com os grandes compradores internacionais. Respaldados por um considerável poder de compra, esses grandes importadores impõem seu estilo de governança às cadeias produtivas sob seu comando (BAZAN; NAVAS-ALEMÁN, 2001), fato que levou Messner e Meyer-Stamer (2000) e Humphrey e Schmitz (2000) a denominar tais relações de quasihierarchy. Com efeito, a realidade da interação entre as partes sempre foi marcada por relações focadas unicamente na redução de custos, o que, segundo Lombardi (2003), não é sustentável ao longo do tempo.

Nesse contexto, não é de estranhar que a criação de condições políticas favoráveis em outras partes do mundo tenha levado ao deslocamento para a Ásia da produção de calçados que originalmente estava sendo realizada no Brasil: a China aumentou sua participação nas importações americanas de pouco mais de 1\% em 1985 para 86,8\% em 2008 (AAFA, 2009). Esse deslocamento na pauta de importações americanas reduziu as possibilidades de negócio para os exportadores brasileiros no referido mercado. Os dados da resenha estatística da Abicalçados (2009) indicam que o Brasil reduziu sua exportação para os Estados Unidos em 62,45\% entre os anos de 1990 e 2008 (de 100,4 milhões em 1990 para 37,7 milhões de pares em 2008).
Confrontados com a concorrência asiática, os calçadistas brasileiros promoveram ações destinadas a aumentar a competitividade do setor. Dentre essas ações podemos citar a elevação dos patamares de qualidade dos produtos e o fornecimento em lotes menores. Conforme Schmitz (1998), essas modificações aumentaram a competitividade da cadeia produtiva brasileira nos mercados de maior valor agregado, de tal maneira que, segundo Knorringa e Schmitz (1999), em pouco tempo atingiu um patamar comparável à italiana. Os dados da Abicalçados (2009) indicam que a queda de 62,45\% no número de pares exportados não se refletiu na mesma proporção em nível de valores transacionados, uma vez que em igual período a receita auferida com a exportação para o referido país teve uma redução de apenas 42,2\% (de US\$ 837,3 milhões em 1990 para US\$ 483,8 milhões em 2008). A menor redução da receita auferida nas exportações (em comparação ao número de pares) é explicada pela elevação de até 75\% no preço médio do par no mesmo período (de US\$ 8,34 em 1990 para US\$12,83 em 2008, com um pico de US\$ 14,61 em 2007).

Analisando os reflexos desse contexto na indústria calçadista de Franca, Garcia, Motta e Amato Neto (2004) comentam que essa adaptabilidade agrada aos grandes importadores, já que para eles compete aos produtores locais apenas a acumulação de capacitações ligadas à melhoria das funções produtivas. A Figura 1 representa a variação do número de pares exportados, da receita com exportações e do preço/par entre os anos de 1990 e 2008.

A questão de pesquisa respondida por este artigo foi: como as alterações mercadológicas recentemente verificadas no cenário de negócios internacionais de calçados, nomeadamente a entrada de competidores chineses, impactaram na indústria calçadista brasileira que produz para grandes importadores americanos? 0 objetivo principal deste artigo foi investigar como os produtores brasileiros de calçados se adaptaram ao novo cenário de

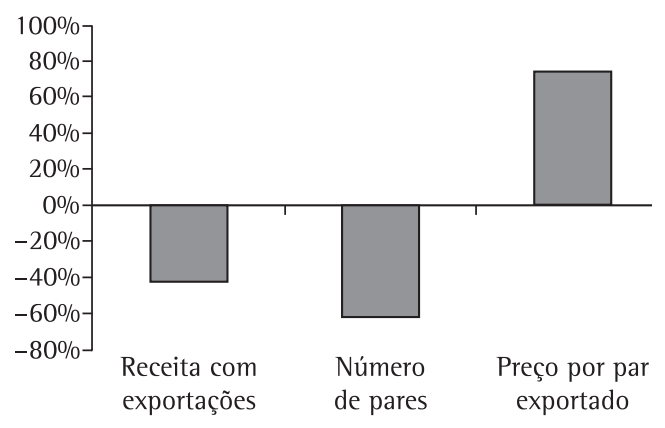

Figura 1. Evolução verificada entre 1990 e 2008. 
competição. Questões do tipo como remetem, segundo Yin (2001), ao método de pesquisa do estudo de caso. Como é a primeira abordagem feita pelos pesquisadores no objeto de pesquisa, optou-se por um estudo de caso exploratório. Este levanta fatos e hipóteses para futuros estudos, que podem ser descritivos, se buscarem associações entre variáveis, ou explanatórios, se acrescentarem explicações (YIN, 2001). Os objetivos específicos foram: (i) identificar na literatura sobre estratégia de produção quais os fatores de competição que se aplicam ao objeto de estudo; (ii) investigar em uma amostra de empresas se houve alteração na importância atribuída por elas mesmas nos fatores que foram anteriormente identificados; e (iii) interpretar os resultados e formular hipóteses para futuros estudos quantitativos do tipo survey.

A principal contribuição deste estudo é do tipo exploratório: formular hipóteses para estudos futuros, mais completos, acerca do impacto das alterações mercadológicas sobre fatores competitivos e estratégia de produção. Segundo Eckstein (1975 apud ROESCH, 1999), um estudo de caso pode contribuir de cinco modos em uma investigação científica. 0 primeiro modo oferece uma descrição profunda e específica de um objeto. 0 segundo interpreta eventuais regularidades como evidências de postulados teóricos mais gerais, ainda não verificados. 0 terceiro modo é heurístico: uma situação é deliberadamente construída para testar uma ideia. 0 quarto faz sondagens plausiveis acerca de uma teoria proposta pelo modo heurístico e o quinto modo, o caso crucial, apoia ou refuta a teoria. Nos três últimos modos, os objetivos são, em graduações, a exploração, a geração e o teste de teorias. Entende-se que a contribuição do presente estudo de caso é do segundo tipo: é mais do que uma descrição de fatos, pois explora regularidades presentes em várias empresas de uma indústria, mas não foi uma situação heuristicamente construída para o teste de uma ideia.
Após a introdução, seguem: (i) revisão sobre fatores competitivos gerais em estratégia de produção; (ii) referencial teórico sobre fatores competitivos específicos para o objeto de pesquisa; (iii) a pesquisa; e (iv) discussão e implicações dos resultados.

Outras pesquisas similares, relacionando estratégia de produção com indústria calçadista, surgem em: Fensterseifer (1995); Fensterseifer e Gomes (1995) e Schmitz (2002).

\section{Dimensões competitivas em estratégia de produção}

Miller e Roth (1994) propuseram um conjunto de dimensões para a análise da competitividade empresarial. Agrupadas nos tópicos preço, flexibilidade, qualidade, entregas e serviço, essas dimensões foram originalmente usadas para classificar empresas de manufatura americana em três grandes grupos de opção estratégica: Marketeers (prospectadores), Caretakers (conservadores) e Innovators (inovadores). A taxonomia de Miller e Roth (1994) se tornou um modelo adotado para avaliação empresarial. Conforme Goh et al. (1997), em poucos anos esse modelo já havia sido replicado em quarenta outros estudos científicos na área de gerência de operações. Um desses estudos foi o de Frohlich e Dixon (2001), que replicou o estudo original de Miller e Roth (1994) com o objetivo de identificar alterações no posicionamento das empresas americanas após alguns anos.

0 Quadro 1 apresenta e organiza fatores de competição e dimensões originalmente propostas pelos autores .

Sob uma perspectiva sistêmica, as dimensões da competitividade de uma unidade produtiva são vistas por alguns pesquisadores como uma síntese conveniente entre os seguintes elementos: custo,

Quadro 1. Dimensões da competitividade de Miller e Roth (1994).

\begin{tabular}{|c|c|l|}
\hline Fator & Dimensão & \multicolumn{1}{|c|}{ Especificação } \\
\hline Preço & Preço baixo & Capacidade de competir em mercados caracterizados pela busca do menor preço \\
\hline \multirow{3}{*}{ Flexibilidade } & Design & Capacidade de proposição de produtos com design inovador \\
\cline { 2 - 3 } & Volume & $\begin{array}{l}\text { Capacidade de responder rapidamente às mudanças de volume demandadas } \\
\text { pelos clientes }\end{array}$ \\
\cline { 2 - 3 } & Diversidade de modelos & Capacidade de fornecer diversos modelos de produtos \\
\hline \multirow{2}{*}{ Qualidade } & Qualidade & Capacidade de oferecer produtos de qualidade superior \\
\cline { 2 - 3 } & Performance & Capacidade de oferecer produtos de alta performance \\
\hline \multirow{2}{*}{ Entregas } & Velocidade & Capacidade de atender os pedidos rapidamente \\
\cline { 2 - 3 } & Pontualidade & Capacidade de entregar produtos dentro do prazo acordado \\
\hline \multirow{3}{*}{ Serviço } & Pós-venda & Capacidade de prover um serviço de pós-vendas adequado \\
\cline { 2 - 3 } & Propaganda & Capacidade de anunciar e promover um produto \\
\cline { 2 - 3 } & Distribuição & Capacidade de distribuir um produto onde ele esteja sendo demandado \\
\hline
\end{tabular}


qualidade, flexibilidade e entregas (SCHMENNER; SWINK, 1998; WARD et al., 1998). Conforme Leong, Snyder e Ward (1990), a definição da eficácia competitiva advém do grau de consistência entre as dimensões elegidas e as correspondentes ações implementadas em estrutura e infraestrutura (tecnologia, recursos humanos, sistemas de qualidade etc.). Entretanto, a seleção de um dado conjunto de dimensões pode implicar a exclusão de outras, fato esse que deu origem a diversas linhas de abordagem teórica, a saber:

- A perspectiva dos trade-offs, que preconiza que os gestores precisam escolher suas prioridades, e depois alocar recursos para viabilizá-las, mesmo que com perdas nas demais (SKINNER, 1969; 1974; HAYES; WHEELWRIGHT, 1984; HILL, 2000; WARD et al., 1998);

- A perspectiva do modelo cumulativo, que considera que a atenção a uma dada dimensão (por exemplo, qualidade) não necessariamente implica o abandono das demais (por exemplo, flexibilidade), já que a melhoria em uma dimensão pode se refletir positivamente em outras (ROTH; MILLER, 1994; CORBETT; VAN WASSENHOVE, 1993; NOBLE, 1995; SZWEJCZEWSKI; MAPES; NEW, 1997); e

- A perspectiva integradora, defendida por Hayes e Pisano (1996) e por Schmenner e Swink (1998), que busca conjugar, em uma única abordagem, as potencialidades das duas anteriores.

Analisando o tema, Boyer e Lewis (2002) concluíram que as dimensões custo, qualidade, flexibilidade e entregas precisam ser consideradas simultaneamente pelas organizações. Os autores igualmente salientam a importância dos trade-offs para o incremento da competitividade de suas unidades, haja vista a necessidade de adequação da empresa aos elementos ambientais (mercado, competidores, tecnologia e agências reguladoras), com o que corroboram Venkatraman e Prescott (1990), Child (1997), Hill
(2000) e Ward e Duray (2000). No caso específico da indústria calçadista nacional exportadora, esses elementos ambientais são potencializados pela imprevisibilidade do ambiente, especialmente no que tange a mix de produtos, tendências de design e volume de vendas.

Ponderando sobre tal contexto, Anand (2004) e Sánchez e Pérez (2005) postulam que a adaptação da estratégia aos elementos ambientais se reflete diretamente no desempenho da organização. Nesse contexto, a capacidade de adaptação à diversidade e à incerteza advinda dos elementos ambientais é denominada por alguns autores como flexibilidade (UPTON, 1994; DE GROOTE, 1994; RILEY; LOCKWOOD, 1997). No caso específico do fator flexibilidade, o Quadro 2 apresenta uma síntese de diferentes dimensões apresentadas na literatura sobre ela. 0 Quadro aponta uma síntese da ideia principal subjacente à dimensão e o autor consultado. Cumpre destacar que Paiva, Carvalho e Fensterseifer (2004) consideram inovação ou inovatividade como fator de competição, e não como uma dimensão da flexibilidade.

\subsection{Dimensões de competição consideradas}

A análise das dimensões anteriormente apresentadas permite concluir que algumas dessas dimensões não se aplicam a uma parcela do setor calçadista dominada pelos grandes importadores, haja vista as condições de governança impostas por eles ao setor. Como exemplos desses elementos citam-se estratégias de pós-vendas, distribuição e propaganda, as quais são executadas pelos próprios importadores. Assim sendo, os pesquisadores, em sessões de grupos focados com especialistas da indústria calçadista indicados pela Assintecal (Associação Brasileira de Empresas para Couro,

Quadro 2. Síntese das dimensões da flexibilidade.

\begin{tabular}{|c|l|l|}
\hline $\begin{array}{c}\text { Dimensão da } \\
\text { Flexibilidade }\end{array}$ & \multicolumn{1}{|c|}{ Especificação } & \multicolumn{1}{c|}{ Referências } \\
\hline Produto & $\begin{array}{l}\text { Capacidade de produção de itens } \\
\text { caracterizados pela constante } \\
\text { mudança em suas especificações }\end{array}$ & $\begin{array}{l}\text { Vickery, Dröge e Markland (1997), Vokurka e 0'leary-Kelly (2000), } \\
\text { Lummus, Duclos e Vokurka (2003), Duclos, Bokurka e Lummus (2003) e } \\
\text { Lummus, Vokurka e Duclos (2005) }\end{array}$ \\
\hline \multirow{2}{*}{ Volume } & $\begin{array}{l}\text { Capacidade de responder } \\
\text { rapidamente às mudanças de } \\
\text { volume demandadas pelos clientes }\end{array}$ & $\begin{array}{l}\text { Cleveland, Schroeder e Anderson (1989), Vokurka e 0'leary-Kelly (2000), } \\
\text { Lummus, Duclos e Vokurka (2003), Duclos, Bokurka e Lummus (2003) e } \\
\text { Lummus, Vokurka e Duclos (2005) }\end{array}$ \\
\hline \multirow{3}{*}{ Inovação } & $\begin{array}{l}\text { Capacidade da empresa de } \\
\text { atender aos prazos especificados } \\
\text { pelos clientes }\end{array}$ & $\begin{array}{l}\text { Sánchez e Pérez (2005), Narasimhan e Das (2000), Vokurka e } \\
\text { O'leary-Kelly (2000), Lummus, Duclos e Vokurka (2003), Duclos, } \\
\text { Bokurka e Lummus (2003) e Lummus, Vokurka e Duclos (2005) }\end{array}$ \\
\hline $\begin{array}{l}\text { Capacidade de rapidamente } \\
\text { introduzir novos produtos com o } \\
\text { objetivo de incrementar ganhos } \\
\text { ou participação de mercado }\end{array}$ & $\begin{array}{l}\text { Lieberman e Montgomery (1988), Robinson, Fornell e Sullivan (1992), } \\
\text { Duclos, Bokurka e Lummus (2003) e Lummus, Vokurka e Duclos (2005) }\end{array}$ \\
\hline
\end{tabular}


Calçados e Artefatos), examinaram e esclareceram os postulados da literatura anteriormente apresentados visando sua adequação ao propósito deste estudo. Em decorrência disso foram eleitos para os estudos de caso os fatores e as dimensões constantes do Quadro 3.

\section{A pesquisa}

A investigação objetivou responder à seguinte questão de pesquisa: Como as alterações mercadológicas recentemente verificadas impactaram nas indústrias calçadistas brasileiras que produzem para grandes importadores americanos? 0 método de pesquisa foi o estudo de caso múltiplo exploratório e indutivo. Esse tipo de abordagem é a mais adequada quando as condições e limites do objeto ou fenômeno em estudo não estão claramente definidos, ou quando a questão de pesquisa versa sobre uma exploração ou construção da teoria (YIN, 2001). Como fontes de evidências foram usadas entrevistas semiestruturadas com gestores, observações diretas e análise de documentos, conforme proposto por Yin (2001) e
Voss, Tsikriktsis e Frohlich (2002). A abordagem principal foi qualitativa. A escolha deu-se com base nos critérios de escolha sintetizados no Quadro 4 (BRYMAN, 1995). Dos critérios apontados, os pesquisadores entendem que há maior ênfase na interpretação dos entrevistados, pois no contexto das organizações o alcance no tempo é maior, não se limitando ao instante da pesquisa. Considerando que várias são as fontes de informações, o ponto de vista do pesquisador pode e deve ser considerado internamente à organização, haja vista que os pesquisadores têm trajetória de atividades e pesquisas conjuntas na indústria. 0 único ponto não totalmente coerente com a abordagem qualitativa é que nesta pesquisa usou-se um quadro teórico que, se não é totalmente rigoroso, também não apresenta muita subjetividade.

Foram entrevistados executivos e empresários atuantes em oito das dezesseis maiores exportadoras que atuam atreladas aos grandes importadores americanos. As entrevistas ocorreram em 2007, sendo que os principais tópicos foram revisados em 2009, não tendo sido encontradas diferenças significativas entre os achados entre os dois cenários em foco. A escolha das empresas participantes

Quadro 3. Dimensões adotadas.

\begin{tabular}{|c|c|l|}
\hline Fator & Dimensão & \multicolumn{1}{c|}{ Referencial teórico } \\
\hline \multirow{3}{*}{ Preço } & Preço & Miller e Roth (1994), Frohlich e Dixon (2001) e Stevenson e Spring (2007) \\
\hline \multirow{3}{*}{ Flexibilidade } & Design & Miller e Roth (1994), Frohlich e Dixon (2001) e Stevenson e Spring (2007) \\
\cline { 2 - 3 } & Volume & $\begin{array}{l}\text { Cleveland, Schroeder e Anderson (1989), Miller e Roth (1994), Frohlich e } \\
\text { Dixon (2001) e Stevenson e Spring (2007) }\end{array}$ \\
\cline { 2 - 3 } & Diversidade de modelos & Miller e Roth (1994), Frohlich e Dixon (2001) e Stevenson e Spring (2007) \\
\cline { 2 - 3 } Qualidade & Produto & Vickery, Dröge e Markland (1997) e Stevenson e Spring (2007) \\
\cline { 2 - 3 } & Qualidade & Miller e Roth (1994), Frohlich e Dixon (2001) e Stevenson e Spring (2007) \\
\hline \multirow{2}{*}{ Entregas } & Performance & Miller e Roth (1994), Frohlich e Dixon (2001) e Stevenson e Spring (2007) \\
\cline { 2 - 3 } & Pontualidade & $\begin{array}{l}\text { Miller e Roth (1994), Frohlich e Dixon (2001), Narasimhan e Das (2000) e Stevenson } \\
\text { e Spring (2007) }\end{array}$ \\
\hline \multirow{2}{*}{ Inovação } & e Das (2000) e Stevenson e Spring (2007) \\
\hline
\end{tabular}

Quadro 4. Adequação das abordagens ao estudo (Fonte: BRYMAN, 1995).

\begin{tabular}{|l|c|c|}
\hline \multicolumn{1}{|c|}{ Aspecto a avaliar } & Pesquisa quantitativa & Pesquisa qualitativa \\
\hline Ênfase na interpretação do entrevistado em relação à pesquisa & Menor & Maior \\
\hline Importância do contexto da organização pesquisada & Menor & Maior \\
\hline Proximidade do pesquisador em relação aos fenômenos estudados & Menor & Maior \\
\hline Alcance do estudo no tempo & Instantâneo & Intervalo maior \\
\hline Número de fontes de dados & Uma & Várias \\
\hline Ponto de vista do pesquisador & Externo à organização & Interno à organização \\
\hline Quadro teórico e hipóteses & Definidas rigorosamente & Menos estruturadas \\
\hline
\end{tabular}


foi feita com base no volume de exportações divulgado pela Abicalçados (2009). A consolidação dos construtos adotados foi feita em consonância com os pressupostos de Strauss e Corbin (1990), e a análise das informações auferidas seguiu a proposta de Eisenhardt (1989) e Miles e Huberman (1994).

Objetivando viabilizar comparações, a seleção das empresas tomou por base a tipologia de organizações proposta por Abecassis-Moedas (2006). Dentre os tipos descritos pela autora foram acessados os seguintes tipos de empresas:

- Empresas de Manufatura Tradicionais (EMT) - São empresas que fazem o design e a produção de seus produtos. Os clientes são as redes de varejo ou proprietárias de grifes famosas que subcontratam a produção de seus itens junto a essas empresas;

- Manufatureiras Sem Indústria (MSI) - São empresas que fazem o design e contratam outras empresas para confeccionar seus produtos. Os clientes são grandes redes de varejo e as empresas detentoras de marcas amplamente reconhecidas pelo público; e

- Empresas Detentoras de Marcas (EDM) - São empresas que fazem o design, terceirizam a produção e vendem seus produtos para lojas de departamentos ou através de lojas próprias.

0 Quadro 5 apresenta os tópicos investigados junto às empresas participantes do estudo. Eles foram derivados dos referenciais apresentados e incluíram diferentes métodos de coleta: entrevistas, análise documental e observação direta acerca das informações auferidas nas entrevistas.

\subsection{Análises das informações}

A análise dos achados inicialmente buscou identificar padrões comuns entre os contextos investigados. Posteriormente, foi realizada análise individual em cada um dos casos. Finalmente, os casos estudados foram observados de forma comparativa e contrastante em cada uma das fontes de evidência coletadas. Os resultados são descritos na sequência, acerca de cada uma das dimensões investigadas. As opiniões dos especialistas e gestores consultados foram compiladas e condensadas em forma de relato comentado.

Quanto à dimensão diversidade de modelos, constatou-se que, para a maioria das empresas, esta aumentou significativamente sua importância após a entrada dos países asiáticos no rol de fornecedores calçadistas. Conforme relatado, os pedidos de grandes lotes e poucos modelos efetivamente foram deslocados para a Ásia, cabendo ao Brasil os pedidos de lotes menores e com grande diversidade de modelos. A comparação dos contextos anterior e atual revelou que hoje em dia é produzida uma quantidade de modelos muitas vezes superior à do passado (de 10 a 20 para 400 em média), fato que justifica o aumento de importância dessa dimensão.

Em decorrência da maior importância da diversidade de modelos, reduziu-se a importância da dimensão volume de produção, já que os modelos dificilmente entram em produção novamente. Atualmente a maioria das coleções possui lotes que oscilam entre 100 e 1.000 pares, números bem inferiores aos 5.000, 10.000 ou mais pares que se produziam no passado. Nesse contexto, a capacidade de resposta às flutuações de demanda de um dado modelo teve sua importância reduzida quando comparada ao cenário anterior.

Redução de importância semelhante ocorreu com a dimensão preço. Com efeito, ele sempre foi, e sempre será, uma preocupação dos entrevistados. Todavia, a capacidade de fornecimento de um maior número de modelos, em baixos volumes, acabou porse transformar em diferencial da região, e isso, associado à produção de itens com maior valor agregado, permitiu uma ampliação nos preços originalmente praticados. Tal

Quadro 5. Tipos de informações coletadas.

\begin{tabular}{|c|c|l|}
\hline Fator & Dimensão & \multicolumn{1}{c|}{ Tópico } \\
\hline \multirow{3}{*}{ Preço } & Preço & Valores praticados no passado e atualmente \\
\hline \multirow{3}{*}{ Qualidade } & Design & Fonte de inspiração para o design da próxima coleção \\
\cline { 2 - 3 } & Volume & Número de pares de uma coleção produzidos no passado e atualmente \\
\cline { 2 - 3 } & Diversidade de modelos & Número de modelos produzidos por temporada no passado e atualmente \\
\cline { 2 - 3 } & Produto & Frequência de alterações nos produtos \\
\cline { 2 - 3 } & Qualidade & $\begin{array}{l}\text { Percepção acerca do nível de qualidade do produto entre os dois cenários } \\
\text { analisados }\end{array}$ \\
\hline \multirow{2}{*}{ Entregas } & Performance & $\begin{array}{l}\text { Percepção acerca da diferença de desempenho requerido entre esses dois } \\
\text { cenários }\end{array}$ \\
\hline & Pelocidade & Demandas de velocidade de entrega entre os dois cenários \\
\hline Inovação & Inovação & Demanda de pontualidade entre esses cenários \\
\hline
\end{tabular}


percepção dos entrevistados é referendada por dados da Abicalçados sobre a evolução do preço médio entre 1990 e 2007 (de US\$ 8,34 para US\$ 14,61), sendo que vem crescendo rapidamente a demanda de produtos na faixa de US\$ 15,00 a US\$ 50,00.

A alta do valor agregado do calçado, e, por conseguinte, do preço médio, refletiu-se no aumento da importância da dimensão qualidade. No que tange especificamente à qualidade do produto, identificou-se que existe uma demanda crescente por artigos que agreguem materiais e processos mais avançados, bem como que conciliem conforto e sofisticação.

As exigências dos mercados de maior valor agregado igualmente se refletiram no aumento da importância das dimensões inovação e flexibilidade de produto. Com efeito, a capacidade de introduzir rapidamente novos produtos destinados a aproveitar oportunidades mercadológicas e a flexibilidade de alterar, em pouco tempo, as especificações deles visando sua melhor adequação às preferências dos consumidores, detectadas em campo, se constituem hoje a maior preocupação de gestores e especialistas. Conforme declarado por vários entrevistados, muitas vezes ocorrem mudanças em materiais e em design, feitas em meio a uma coleção, fato que introduz uma complexidade até bem pouco tempo inexistente no setor.

As informações coletadas acerca das dimensões performance e pontualidade revelam que, para a maioria dos entrevistados, elas não se alteraram nos últimos anos, haja vista que as regras impostas pelos importadores ante tais quesitos permanecem rígidas. 0 mesmo não pode ser dito da dimensão velocidade, que aumentou de importância em decorrência do aumento da dinâmica das transações na indústria.

Por fim, os pesquisadores obtiveram a percepção do setor acerca da dimensão design, a qual não apresentou alterações em sua importância ao longo do tempo. As informações auferidas ratificam a percepção de que as empresas submetidas à tutela dos grandes importadores ainda não dedicam maior importância estratégica a essa dimensão, já que, segundo os entrevistados, a preocupação com o design é de responsabilidade dos agentes de importação. Contudo, algumas empresas entrevistadas manifestaram interesse em desenvolver essa dimensão, sendo que algumas delas já fazem em projetos específicos. Dentre esses projetos merece destaque o incentivo ao design nacional e a busca por nichos pouco explorados pelos concorrentes asiáticos. Assim sendo, conclui-se que essa dimensão não se alterou ao longo dos tempos nas empresas calçadistas que trabalham associadas aos grandes importadores, apesar dos esforços feitos por muitas associações empresariais e pelos órgãos de governo.

0 Quadro 6 apresenta uma síntese das informações coletadas.

A análise do Quadro 6 permitiu que se agrupassem as alterações em três grandes grupos, conforme Quadro 7. As dimensões diversidade

Quadro 6. Síntese das informações apresentadas.

\begin{tabular}{|c|c|c|c|}
\hline Tópico & Dimensão & Contexto anterior & Contexto atual \\
\hline Preço & Preço baixo & US\$ 8,34 (1990) & $\begin{array}{l}\text { Média de US\$14,61 (em 2007). Vendas em ascensão } \\
\text { na faixa de US\$15 a } 50 .\end{array}$ \\
\hline \multirow{4}{*}{ Flexibilidade } & Design & Fornecido pelos importadores & $\begin{array}{l}\text { Importadores ainda fornecem o design, contudo o } \\
\text { design nacional lentamente vem ganhando espaço }\end{array}$ \\
\hline & Volume & $5.000-10.000$ pares & $100-1.000$ pares \\
\hline & $\begin{array}{l}\text { Diversidade de } \\
\text { modelos }\end{array}$ & $\begin{array}{l}\text { Entre } 10 \text { e } 20 \text { modelos em } \\
\text { produção por temporada }\end{array}$ & Média de 400 modelos em produção por temporada \\
\hline & Produto & $\begin{array}{l}\text { Alterações eram raras em uma } \\
\text { dada coleção }\end{array}$ & Alterações são constantes em meio à coleção \\
\hline \multirow[t]{2}{*}{ Qualidade } & Qualidade & $\begin{array}{l}\text { Qualidade compatível com a faixa } \\
\text { de preços praticada à época. }\end{array}$ & $\begin{array}{l}\text { Demanda por materiais e processos cada vez mais } \\
\text { sofisticados e variados. Crescente atenção a atributos } \\
\text { como conforto e sofisticação. }\end{array}$ \\
\hline & Performance & $\begin{array}{l}\text { Crítica para a manutenção do } \\
\text { cliente }\end{array}$ & Crítica para a manutenção do cliente \\
\hline \multirow[t]{2}{*}{ Entregas } & Velocidade & $\begin{array}{l}\text { Baixa importância em função do } \\
\text { maior tempo de preparação da } \\
\text { produção. }\end{array}$ & $\begin{array}{l}\text { Estratégica em função da necessidade de se produzir } \\
\text { em sintonia com a demanda. }\end{array}$ \\
\hline & Pontualidade & $\begin{array}{c}\text { Atrasos podem levar ao } \\
\text { desligamento do fornecedor }\end{array}$ & Atrasos podem levar ao desligamento do fornecedor \\
\hline Inovação & lnovação & $\begin{array}{l}\text { Coleções eram alteradas a cada } \\
\text { temporada }\end{array}$ & $\begin{array}{l}\text { Coleções são alteradas em meio à temporada com } \\
\text { vistas ao atendimento das demandas de mercado. }\end{array}$ \\
\hline
\end{tabular}




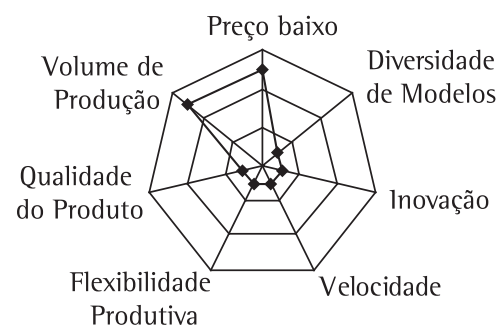

Figura 2. Importância categórica das dimensões antes do aumento da concorrência.

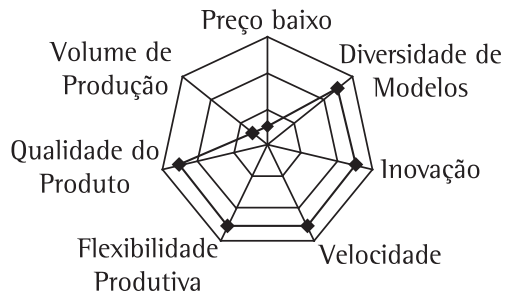

Figura 3. Importância categórica das dimensões depois do aumento da concorrência.

Quadro 7. Agrupamento das informações apresentadas.

\begin{tabular}{|c|c|}
\hline $\begin{array}{c}\text { Alteração } \\
\text { verificada }\end{array}$ & Dimensões \\
\hline $\begin{array}{c}\text { Aumento da } \\
\text { importância } \\
\text { estratégica }\end{array}$ & $\begin{array}{c}\text { Diversidade de modelos, velocidade, } \\
\text { qualidade, inovação e flexibilidade } \\
\text { de produto }\end{array}$ \\
\hline $\begin{array}{c}\text { Sem } \\
\text { alterações }\end{array}$ & Design, performance e pontualidade \\
\hline $\begin{array}{c}\text { Redução da } \\
\text { importância } \\
\text { estratégica }\end{array}$ & Preço e volume de produção \\
\hline
\end{tabular}

de modelos, velocidade, qualidade, inovação e flexibilidade de produto tiveram suas importâncias aumentadas, segundo a maioria dos entrevistados. As dimensões preço e volume de produção tiveram sua importância diminuída, como efeito de trade-offs ocorridos na indústria. As dimensões design, performance e pontualidade não parecem ter tido suas importâncias alteradas.

Após esta etapa, os Quadros 6 e 7 foram submetidos à análise dos entrevistados para suas críticas, em sessões de grupos focados, mediados pelos pesquisadores. Houve maioria de concordâncias com o Quadro 7. Para facilitar a comunicação dos achados, estes foram organizados em Gráficos do tipo radar expressando a variação nas importâncias. Foram omitidas as dimensões design, performance e pontualidade por não terem sofrido alteração. Adotou-se a seguinte regra: dimensões com importância aumentada em um dado contexto obtiveram nota máxima, enquanto dimensões com importância reduzida tiveram nota mínima. Quanto mais externa a representação gráfica da dimensão, maior a sua importância. 0 resultado é apresentado nas Figuras 2 e 3. A visualização simultânea das duas Figuras é capaz de comunicar com mais precisão a modificação estratégica que pode ter ocorrido na indústria com o aumento da competição, após a entrada de competidores chineses no mercado exportador .

\section{Conclusões}

Objetivando avaliar as alterações nas dimensões da competitividade nas empresas calçadistas voltadas à exportação após a entrada dos países asiáticos no rol de fornecedores mundiais de calçados, o presente estudo investigou a evolução da importância das seguintes dimensões: preço, design, volume, diversidade de modelos, produto, qualidade, performance, velocidade e pontualidade.

Em síntese, este estudo de caso permitiu formular uma hipótese de pesquisa, que poderá ser testada em futuros estudos. Após a entrada de competidores chineses, as dimensões de competição diversidade de modelos, velocidade, qualidade, inovação e flexibilidade de produto aumentaram de importância; as dimensões design, performance e pontualidade mantiveram suas importâncias; e as dimensões preço e volume de produção diminuíram. Como continuidade do trabalho, não apenas para confirmar ou refutar a hipótese, mas também para quantificá-la, foi proposta às lideranças do setor uma pesquisa quantitativa do tipo survey. Nessa pesquisa, serão enviados questionários às empresas da indústria. Seus gestores serão convidados a responder quantificando, em escala categórica (total; alta; média; baixa; nula), a importância dada às dimensões investigadas antes e depois do acirramento da concorrência e da mudança de perfil do mercado.

Conforme identificado, os exportadores brasileiros conseguiram aumentar o preço médio do par exportado alterando a atenção dada a algumas dimensões que configuram a competitividade organizacional. Entre elas, merece destaque a recente priorização das dimensões diversidade de modelos, velocidade, qualidade, inovação e flexibilidade de produto. A mudança nessas dimensões permitiu que as empresas locais se diferenciassem de seus competidores asiáticos e assim encontrassem novos espaços de atuação. 
0 aumento da importância dessas dimensões competitivas, por sua vez, acabou por demandar a redução da atenção dedicada a outras, como preço e volume de produção, dimensões que definiam a competitividade dos exportadores até a entrada dos asiáticos no rol de fornecedores de calçados para os mercados da Europa e dos Estados Unidos.

Outras dimensões como design, performance e pontualidade não sofreram alteração no que tange às suas importâncias estratégicas. Entre elas merece destaque a questão do design, o qual, apesar dos esforços empreendidos por associações empresariais e órgãos governamentais, ainda permanece fortemente controlado pelos importadores tradicionais nesse ramo da indústria calçadista. Contudo, o presente estudo identificou sinais de mudança no que tange a essa questão, especialmente no que se refere à valorização do design by Brasil no plano internacional.

A focalização em mercados de nicho foi outra tendência detectada no presente estudo, uma vez que os baixos volumes e a grande diversidade de modelos que caracterizam os mercados segmentados os tornam pouco atrativos aos fornecedores localizados na Ásia.

As modificações ora identificadas suscitam outras importantes reflexões científicas, em especial no que tange às alterações que tais mudanças podem ter provocado ao longo da cadeia de suprimentos das empresas estudadas, mais especificamente nas fornecedoras de componentes para calçados. Nesse contexto, identifica-se aqui a necessidade de realizar novos estudos científicos destinados a avaliar tais impactos ao longo da referida cadeia, bem como acerca da melhor forma de gerenciamento dos sistemas produtivos atuais visando sua adequação aos novos requisitos de flexibilidade, qualidade, entregas e inovação que ora caracterizam o mercado exportador de calçados.

Por fim, é sempre oportuno ressaltar que os resultados auferidos pela presente investigação não são extensíveis às demais empresas produtoras de calçados da região. Na verdade, as alterações nas dimensões relatadas no presente trabalho somente se aplicam às exportadoras que se encontram tuteladas pelos grandes importadores americanos. A extrapolação dos resultados aqui apresentados para outros contextos deverá demandar a execução de novos estudos científicos.

\section{Referências}

ABECASSIS-MOEDAS, C. Integrating design and retail in the clothing value chain: An empirical study of the organization of design. International Journal of
Operations \& Production Management, v. 26, n. 4, p. 412-428, 2006.

AMERICAN APPAREL AND FOOTWEAR ASSOCIATION AAFA. US apparel and footwear imports. Arlington, 2009. Disponivel em: <http://www.apparelandfootwear.org > Acesso em: 13 ago. 2009.

ANAND, G.; WARD, P. Flexibility and performance in manufacturing: coping with dynamic environments. Production and Operations Management, v. 13, n. 4, p. 369-386, 2004.

ASSOCIAÇÃO BRASILEIRA DAS INDÚSTRIAS DE CALÇADOS - ABICALÇADOS. Resenha Estatística 1990 - 2008. Novo Hamburgo, 2009. Disponível em: <http://www. abicalcados.org.br>. Acesso em: 25 jul. 2009.

BAZAN, L.; NAVAS-ALEMÁN, L. Comparing chain governance and upgrading patterns in the Sinos Valley, Brazil. In: LOCAL UPGRADING IN GLOBAL CHAINS, 1., 2001, Sussex. Anais... Brighton: Institute of Development Studies, 2001. p. 1-26.

BOYER, K.; LEWIS, M. Competitive priorities: investigating the need for trade offs in operations strategy. Production and Operations Management, v. 11, n. 1, p. 9-21, 2002.

CHILD, J. Strategic choice in the analysis of actions, structure, organizations, and environment. Organization Studies, v. 18, n. 1 , p. 43-76, 1997.

CLEVELAND, G.; SCHROEDER, R.; ANDERSON, J. A theory of production competence. Decision Sciences, v. 20, n. 4, p. 655-668, 1989.

CORBETT, C.; VAN WASSENHOVE, L. Trade-Offs? What Trade-Offs? Competence and Competitiveness in Manufacturing Strategy. California Management Review, v. 35, n. 4, p. 107-122, 1993.

DE GROOTE, X. The flexibility of production processes: a general framework. Management Science, v. 40, n. 7, p. 933-45, 1994.

DUCLOS, L. K.; VOKURKA, R. J.; LUMMUS, R. R. A conceptual model of supply chain management. Industrial Management \& Data Systems, v. 103, n. 5-6, p. 446-456, 2003.

EISENHARDT, K. Building theory from case study research. Academy of Management Review, v. 14, n. 4, p. 532-550, 1989.

FENSTERSEIFER, J. Estratégia de produção na indústria calçadista: análise do best-practice. ln: FENSTERSEIFER, J. E. (Org.). O complexo calçadista em perspectiva: tecnologia e competitividade. Porto Alegre: Ortiz, 1995. p. $183-216$.

FENSTERSEIFER, J. E.; GOMES, J. Estratégia de produção na indústria calçadista do vale do rio dos sinos: análise do "best-practice". In: ENCONTRO DA ASSOCIAÇÃO NACIONAL DE PÓS-GRADUAÇÃO E PESQUISA EM ADMINISTRAÇ̃O, 19., 1995, João Pessoa. Anais...

FROHLICH, M.; DIXON, J. A taxonomy of manufacturing strategies revisited. Journal of Operations Management, v. 19, n. 5, p. 541-558, 2001.

FURTAD0, J. Globalização das cadeias produtivas no Brasil. São Carlos: UFSCar, 2003. 245 p.

GARCIA, R.; MOTTA, F. G.; AMATO NETO, J. Uma análise das características da estrutura de governança em sistemas locais de produção e suas relações com a cadeia global. Gestão e Produção, v. 11, n. 3, p. 343-354, 2004. 
GEREFFI, G. International trade and industrial upgrading in the apparel commodity chain. Journal of International Economics, v. 48, n. 1, p. 31-70, 1999.

$\mathrm{GOH}$, C. et al. Evaluating and classifying POM journals. Journal of Operations Management, v. 15, n. 2, p. 123-138, 1997.

HAYES, R.; PISANO, G. Manufacturing Strategy at the Intersection of Two Paradigm Shifts. Production and Operations Management, v. 5, n. 1, p. 25-41, 1996.

HAYES, R.; WHEELWRIGHT, S. Restoring our competitive edge: competing through manufacturing. New York: John Wiley and Sons, 1984. 330 p.

HILL, T. Manufacturing strategy: text and cases. Boston: McGraw Hill, 2000. 287 p.

HUMPHREY, J.; SCHMITZ, H. Governance and upgrading: linking industrial cluster and global value chain. Brighton: University of Sussex, 2000. 40 p.

KNORRINGA, P.; SCHMITZ, H. Learning from Global Buyers. Brighton: University of Sussex, 1999. $34 \mathrm{p}$.

KRUGMAN, P. What's new about the New Economic Geography? Oxford Review of Economic Policy, v. 14, n. 2, p. 7-17, 1998.

LEONG, G.; SNYDER, D.; WARD, P. Research in the process and content of manufacturing strategy. Omega, v. 18, n. 3, p. 109-122, 1990.

LIEBERMAN, M.; MONTGOMERY, D. First mover advantages. Strategic Management Journal, v. 9, n. 1, p. 41-58, 1988.

LOMBARDI, M. The Evolution of Local Production Systems: the emergence of the "invisible mind" and the evolutionary pressures towards more visible "minds". Research Policy, v. 32, n. 9, p. 1443-1462, 2003

LUMMUS, R. R.; DUCLOS, L. K.; VOKURKA, R. J. Supply chain fexibility: building a new model. Global Journal of Flexible Systems Management, v. 4, n. 4, p. 1-13, 2003.

LUMMUS, R. R.; VOKURKA, R. J.; DUCLOS, L. K. Delphi study on supply chain fexibility. International Journal of Production Research, v. 43, n. 13, p. 2687-708, 2005.

MESSNER D.; MEYER-STAMER, J. Governance and Networks. tools to study the dynamics of Clusters and Global Value Chains. Duisburg: INEF, 2000. 32 p.

MILES, H.; HUBERMAN, M. Qualitative data analysis: a sourcebook. Beverly Hills: Sage Publications, 1994.

MILLER, J.; ROTH, A. A taxonomy of manufacturing strategies. Management Science, v. 40, n. 3, p. 285-304, 1994.

NARASIMHAN, R.; DAS, A. An empirical examination of sourcing's role in developing manufacturing fexibilities. International Journal of Production Research, v. 38, n. 4, p. 875-93, 2000.

NOBLE, M. manufacturing strategy: testing the cumulative model in a multiple country context. Decision Sciences, v. 26, n. 5, p. 693-721, 1995.

PAIVA, E.; CARVALHO, J.; FENSTERSEIFER, J. E. Estratégia de produção e operações. Porto Alegre: Bookman, 2004.

PICCINıNI, V. Mudanças na indústria calçadista brasileira: novas tecnologias e globalização do mercado. Revista Eletrônica de Administração, v. 1, n. 1, p. 1-30, 1995.

PORTER, M. Clusters and the economics and competition. Harvard Business Review, v. 76, n. 6, p. 77-90, 1998.
RILEY, M.; LOCKWOOD, A. Strategies and measurement for workforce flexibility: an application of functional flexibility in a service setting. International Journal of Operations \& Production Management, v. 17, n. 4, p. 413-419, 1997.

ROBINSON, W.; FORNELL, C.; SULLIVAN, M. Are market pioneers intrinsically stronger than later entrants? Strategic Management Journal, v. 13, n. 6, p. 609-624, 1992.

SÁNCHEZ, A.; PÉREZ, M. Supply chain flexibility and firm performance. International Journal of Operations \& Production Management, v. 25, n. 7, p. 681-700, 2005.

SCHMITZ, H. Collective efficiency and increasing returns. Brighton: University of Sussex, 1997. 28 p.

SCHMITZ, H. Responding to global competitive pressure: local co-operation and upgrading in Sinos Valley, Brazil. Brighton: University of Sussex, 1998. $32 \mathrm{p}$.

SCHMITZ, H.; NADVl, K. Clustering and industrialization: introduction. World Development, v. 27, n. 9, p. 1503-1514, 1999.

SCHMENNER, R.; SWINK, M. On theory in operations management. Journal of Operations Management, v. 17, n. 1, p. 97-113, 1998.

SZWEJCZEWSKI, M.; MAPES, J.; NEW, C. Delivery and Trade-Offs. International Journal of Production Economics, v. 53, n. 3, p. 323-330, 1997.

SCHMITZ, H. Sistemas locais de produção e desafios globais: a indústria calçadista do Vale dos Sinos, no Rio Grande do Sul. In: CASTILHOS, C. (Org.). Programa de apoio aos sistemas locais de produção: a construção de uma política publica no RS. Porto Alegre: FEE, 2002.

SCOTT, A. The geographic foundations of industrial performance. In: CHANDLER, A.; HAGSTRON, P.; SOLVELL, 0. The dynamic firm: the role of technology, strategy, organization, and regions. 0xford: Oxford University Press, 1998. 488 p.

SERVIÇO BRASILEIRO DE APOIO À PEQUENA E MICRO EMPRESA - SEBRAE. Tecnologia e competitividade: diagnóstico da indústria calçadista do Rio Grande do Sul. Porto Alegre, 1992.

SKINNER, W. Manufacturing: missing link in corporate strategy. Harvard Business Review, v. 3, p. 136-145, 1969.

SKINNER, W. The Focused Factory. Harvard Business Review, v. 3, p. 113-119, 1974.

SONOBE, T.; AKOTEN, J.; OTSUKA, K. The development of the footwear industry in Ethiopia: how different is it from the East Asian experience? Tokyo: Foundations for Advanced Studies on International Development, 2006. (Working Paper)

STEVENSON, M.; SPRING, M. Flexibility from a supply chain perspective: definition and review. International Journal of Operations \& Production Management, v. 27, n. 7, p. 685-713, 2007.

STRAUSS, A.; CORBIN, J. Basics of qualitative research: grounded theory procedures and techniques. Newbury Park: Sage Publications, 1990.

STURGEON, T. Modular production network: a new american model of industrial organization. Industrial and Corporate Change, v. 3, n. 11, p. 451-496, 2002. 
SUZIGAN, W. et al. Aglomerações industriais no estado de São Paulo. Economia Aplicada, v. 5, n. 4, p. 695-717, 2001a.

SUZIGAN, W. et al. Sistemas locais de produção no Estado de São Paulo: o caso da indústria de calçados de Franca. In: TIRONI, L. F. (Coord.). Industrialização descentralizada: sistemas industriais locais. Brasília: IPEA, 2001b.

UPTON, D. The management of manufacturing flexibility. California Management Review, v. 36, n. 1, p. 72-89, 1994.

VENKATRAMAN, N.; PRESSCOTT, J. Environment-strategy coalignment: An empirical test of its performance implications. Strategic Management Journal, v. 11, n. 1, p. 1-24, 1990.

VICKERY, S.; DRÖGE, C.; MARKLAND, R. Dimensions of manufacturing strength in the furniture industry. Journal of Operations Management, v. 15, n. 4, p. 317-330, 1997.

VOKURKA, R. J.; O'LEARY-KELLY, S. W. A review of empirical research on manufacturing flexibility. Journal of Operations Management, v. 18, p. 485-501, 2000.
VOSS, C.; TSIKRIKTSIS, N.; FROHLICH, M. Case research in operations management. Journal of Operations and Production Management, v. 22, n. 2, p. 195-219, 2002.

YIN, R. Case study research. London: Sage, 2001.

WARD, P. et al. Competitive Priorities in Operations Management. Decision Sciences, v. 29, n. 4, p. 1035-1046, 1998.

WARD, P.; DURAY, R. Manufacturing strategy in context: Environment, competitive strategy and manufacturing strategy. Journal of Operations Management, v. 18, n. 2, p. 123-138, 2005.

\section{Agradecimento}

Os autores desejam reconhecer a importância para o resultado alcançado da Assintecal e das empresas, gestores e especialistas que aceitaram participar da pesquisa - parte dela financiada pelo CNPq.

\title{
Changes in competitive factors in footwear export industry due to arrival Asian producers
}

\begin{abstract}
The paper presents an analysis of the changes observed in competitive factors in the footwear industry aimed at the Brazilian-based export industry, due to the arrival of Asian producers, the Chinese in particular, in the market. The research method was a qualitative exploratory case study. The main research techniques were semi-structured interviews and focus groups. Managers, experts and academics involved in the companies participated. As a result, we discovered that the impact of these new producers has been to sharpen the following competitive dimensions: diversity of models, quality, innovation, speed of delivery and flexibility. The dimensions of volume and price declined in importance. The dimensions of design, performance and reliability of delivery remain unchanged. The paper's main contribution is to postulate a research hypothesis to be tested in a future survey dealing with competitive dimensions in the industry.
\end{abstract}

\section{Keywords}

Footwear industry. Production strategy. Clusters. Supply chain. Competitiveness. 